\title{
Characteristics of Basolateral Amygdala Neuronal Firing on a Spatial Memory Task Involving Differential Reward
}

\author{
Wayne E. Pratt and Sheri J. Y. Mizumori \\ University of Utah
}

\begin{abstract}
Previous research has shown that spatial, movement, and reward information is integrated within the ventral striatum (VS). The present study examined the possible contribution of the basolateral nuclei of the amygdala (BLA) to this interaction by examining behavioral correlates of BLA neurons while rats performed multiple memory trials on an 8-arm radial maze. Alternate arms consistently held 1 of 2 different amounts of reward. Recorded cells were correlated with motion, auditory input, space, and reward acquisition. Reward-related units were found that anticipated reward encounter, that responded during reward consumption, and that differentiated between high and low reward magnitude. This is consistent with the hypothesis that BLA neurons may provide the VS with reward-related information that could then be integrated with spatial information to ultimately affect goal-directed behavior.
\end{abstract}

Past research into the role of the amygdala in animal behavior has demonstrated that it is an important substrate for the association of cues with their affective significance. Lesions of the amygdala have been shown to impair fear conditioning (Kapp, Frysinger, Gallagher, \& Haselton, 1979; LeDoux, Cicchetti, Xagoraris, \& Romanski, 1990), block the augmentation of acoustic startle by cues previously paired with shock (Hitchcock \& Davis, 1986, 1987), and impair secondary conditioning of cues to previously paired rewarded cues (Cador, Robbins, \& Everitt, 1989; Everitt, Cador, \& Robbins, 1989; Gaffan \& Harrison, 1987; Hatfield, Han, Conley, Gallagher, \& Holland, 1996). Electrophysiological recordings from the amygdala have shown that neurons within the amygdala fire in response to rewarding and aversive events, as well as to cues that have been paired with those events (Muramoto, Ono, Nishijo, \& Fukuda, 1993; Nishijo, Ono, \& Nishino, 1988a, 1988b; Sanghera, Rolls, \& Roper-Hall, 1979). Although these studies have provided much information about the function of the amygdala in classical conditioning, less is known about the amygdala's role in mediating behavior during animal navigation.

Animals with amygdala lesions are not impaired on the win-shift task on an eight arm radial maze (McDonald \& White, 1993). Rather, recent study has shown that hippocampal connections to the nucleus accumbens and prefrontal cortex are critical for the working-memory aspect of spatial navigation (Floresco, Seamans, \& Phillips, 1997). On the other hand, research using the conditioned place preference

Wayne E. Pratt and Sheri J. Y. Mizumori, Department of Psychology, University of Utah.

This work was supported by National Institutes of Health Grant AG09299 and National Science Foundation Grant IBN 9514880. We thank Karen Burke for her help with histology and Caroline Hutchings for assistance in collecting a portion of the data.

Correspondence concerning this article should be addressed to Sheri J. Y. Mizumori, Department of Psychology, University of Utah, 390 S. 1530 E. Room 502, Salt Lake City, Utah 84112. Electronic mail may be sent to mizumori@behsci.utah.edu. paradigm has demonstrated that animals with lesions to the amygdala are impaired in their ability to associate places in an environment with reward (McDonald \& White, 1993). Furthermore, it appears that neuroanatomical connections between, specifically, the basolateral nuclei of the amygdala (BLA) and the ventral striatum (VS) are essential for such associations (Everitt, Morris, O'Brien, \& Robbins, 1991). Similarly, BLA lesions block conditioned fear to both tones and environments paired with shock; in contrast, ventral angular bundle lesions of hippocampal efferents block only contextual conditioning (Maren, Aharonov, \& Fanselow, 1996; Maren \& Fanselow, 1995). These studies suggest that the BLA may be important in associating regions of space with rewarding or aversive aspects of an environment.

The brain area that has been most implicated in the manipulation of spatial information and the navigational abilities of mammals is the hippocampus (HPC). Rats with damaged hippocampi are unable to remember the location of a platform in a Morris water maze (Morris, Garrud, Rawlins, \& O'Keefe, 1982) and are severely deficient in remembering which arms they have visited in an eight arm radial maze (Olton, Branch, \& Best, 1978). Recordings from the neurons of rat HPC show place-specific firing (McNaughton, Barnes, \& O'Keefe, 1983; Muller, Kubie, \& Ranck, 1987; O'Keefe \& Dostrovsky, 1971; Olton et al., 1978; Ranck, 1973). Complex spike cells within the HPC fire when the rat occupies a specific place in its environment during spatial tasks. Anatomical studies have shown that projections from the HPC and BLA converge onto similar regions of the striatum (McDonald, 1991; McGeorge \& Faull, 1989). The BLA projects to the striatum in a topographical fashion, with its anterior to posterior regions projecting, respectively, to the lateral and medial VS (Kelly, Domesick, \& Nauta, 1982; McDonald, 1991). The VS also receives dense innervation by output regions of the HPC (Groenewegen, VermeulenVan der Zee, Te Korshchot, \& Witter, 1987; Kelley \& Domesick, 1982). This area of the striatum has been extensively studied as a potential limbic-motor integration site. Stimulation of the amygdala and HPC can elicit 
responses in nucleus accumbens neurons (Yang \& Mogenson, 1985; Yim \& Mogenson, 1982). Intracellular recordings have shown that stimulation of both input regions can activate single cells within the nucleus accumbens (Finch, 1996; O'Donnell \& Grace, 1995). Furthermore, stimulation of either the BLA or HPC has been shown to have inhibitory effects on the ventral pallidum, a premotor structure. Blocking synaptic input to the nucleus accumbens from either the HPC or the BLA can attenuate this effect (Yang \& Mogenson, 1985; Yim \& Mogenson, 1983).

Such connections provide the HPC and BLA with a means to affect ongoing behavior. Previously, Lavoie and Mizumori (1994) recorded medial VS neurons during a spatial memory task to examine their role during navigation. It was found that the VS contained place-specific neurons, movement-related neurons, and reward-related neurons. A small number showed sensitivity to two of these groups, suggesting that space, movement, and reward information converge at both the structural and cellular level of the medial VS.

It is likely that the spatial information encoded by such cells originates in the HPC, given the relatively similar nature of place-specific cells in both neuronal structures (Lavoie \& Mizumori, 1994). However, the source of input for the reward correlate remains unclear. Although some evidence has accumulated that HPC place fields may move with the location of a rewarded site in a relatively sparsely cued spatial environment (Breese, Hampson, \& Deadwyler, 1989), at least one study has examined changing reward location within a richly spatial environment and found no effect on the place fields of complex spike cells of the HPC (Speakman \& O'Keefe, 1990). This suggests that information concerning reward may be obtained by the medial VS via other means.

Given the history of the BLA as a substrate that pairs cues with incentive value, its connectivity with the VS, and behavioral evidence suggesting a role for the BLA in spatial associations, it is argued that the BLA may be one source of reward-related information that is relevant for accurate goal-oriented navigation. If this is the case, then recording the activity of BLA neurons during a spatial learning task should reveal reward-sensitive correlates. The present study sought to examine the nature of neuronal firing within the BLA while rats performed a spatial navigation task on an eight arm radial maze, sections of which held differential rewards.

\section{Method \\ Subjects}

Subjects consisted of 6 successfully implanted male Long-Evans rats, bred and housed in the laboratory. Rats were given 2-3 days to acclimate to individual housing in a new colony room before being reduced and maintained at $80 \%$ body weight. Rats were handled daily for no fewer than 7 days prior to beginning behavioral training. Water was available at all times. Rats were maintained on a 12-hr light-dark cycle (lights on at 7 a.m.) in a controlled temperature environment of $70^{\circ} \mathrm{F}$. All behavioral testing was done during the rat's light phase.

\section{Apparatus}

A semiautomated eight arm radial maze was used for this experiment, consisting of eight black Plexiglas runways $(58 \times$ $5.5 \mathrm{~cm})$ radiating from a center platform $(19.5-\mathrm{cm}$ diameter) and supported $79 \mathrm{~cm}$ from the floor. The internal segments of each arm could be raised or lowered by remote control to provide access to the arms from the maze center.

The experiment was conducted in one of three environments. One room had the benefit of controlled cues, and consisted of a 62 in. long $\times 62$ in. wide $\times 120$ in. deep space marked off by black drapes. On these drapes were visual cues such as a broom, flag, and poster. This room was lit by four $15 \mathrm{~W}$ bulbs located at the corners of the room, facing the ceiling. A second room was $178 \mathrm{in}$. long $X$ 91 in. wide $\times 111$ in. deep, lit by a $40 \mathrm{~W}$ light in one corner of the room. Additional visual cues consisted of a lamp, table, chair, door, and the experimenter. During the course of the experiment, this room was converted into a controlled-cue environment similar to the formerly described room.

\section{Behavioral Training}

Upon reaching $80 \%$ body weight, the rats were placed on the maze and given access to all eight arms with an abundant supply of chocolate milk on each arm. Once the rat had visited and consumed reward on all eight arms, chocolate milk was subsequently deposited only at the end of each arm. Maximum time per day on the maze was $1 \mathrm{hr}$.

Once it was established that the rat would visit each arm, rats were given trials in which they were presented with all eight arms, and allowed to visit each for chocolate milk reward (five drops). As the rats left each arm, it was lowered, and the rat was not allowed to visit the same arm twice during each trial. One trial consisted of a visit to all eight rewarded locations. The intertrial interval was 2 min. This training continued until eight such trials were completed in a $1-h r$ period.

When this criterion was met, the rats were trained to perform a partial forced-choice memory task. Four arms were raised in a sequence determined from a table of random numbers. After presentation of the fourth arm, all arms were raised. The memory portion of the task entailed entering only the four arms that had chocolate milk remaining. During this phase the arms were not lowered as rats left the arms, and any return entries were counted as errors. The trial ended once all eight arms were visited. Beginning with this training, arms were baited with large or small rewards (5 drops or 1 drop, respectively) on odd or even arms. Determination of whether large reward was placed on odd or even arms was randomly determined for each rat, and remained consistent throughout the experiment unless otherwise noted. Once rats could perform eight such trials per day for 7 consecutive days, training ceased and electrodes were surgically implanted.

Rats that experienced a permanent change in the testing environment at any point within the experiment $(n=3)$ were retrained until they performed at optimal levels for 7 days before the experiment was continued.

\section{Electrode Construction}

The stereotrode and microdrive design of McNaughton and colleagues (McNaughton, Barnes, Meltzer, \& Sutherland, 1989; McNaughton, O'Keefe, \& Barnes, 1983) was adopted for this experiment. Two lacquer-coated tungsten wires twisted together and coated with Epoxilite were threaded through a 30-gauge cannula, leaving 1-2 mm of wire exposed at the bottom. Two such 
cannulas were placed approximately $1 \mathrm{~mm}$ apart on each microdrive. One microdrive was implanted over each hemisphere. Prior to surgery, the stereotrode tips were cut an an angle of $45^{\circ}$ and gold plated to an impedance of $50-150 \mathrm{KOhm}$ (tested at $1 \mathrm{KHz}$ ). Reference electrodes were constructed from $114 \mu \mathrm{m}$ Teflon-coated stainless steel wire. One or two ground leads of $250 \mu \mathrm{m}$ Tefloncoated stainless steel wire were soldered to a jeweler's screw. Amphenol pins were crimped onto the stripped ends of recording electrodes and ground wires. During surgery, pins were inserted into one or two plastic nine-pin connectors, one per hemisphere. Rats that received one head plug $(n=3)$ were recorded one hemisphere at a time, and required connecting of the second hemisphere halfway through the experiment.

\section{Surgical Procedure}

Following $24 \mathrm{hr}$ of food and water deprivation, rats were anesthetized with sodium pentobarbital $(40 \mathrm{mg} / \mathrm{kg}$ initial dose with $0.05 \mathrm{cc}$ supplements given as needed) and secured in a rat stereotaxic apparatus (Kopf). Atropine sulfate was administered ( $0.2 \mathrm{cc}$ per rat) to minimize respiratory distress. Burr holes were drilled through the skull and two stereotrodes per hemisphere were implanted above the BLA (from bregma: $2.4-3.6 \mathrm{~mm}$ posterior, \pm 5 $\mathrm{mm}$ lateral, $6 \mathrm{~mm}$ ventral to dura). One or two reference electrodes (one for each head plug) were placed in an accessible quiet region of the brain, and one or two ground screws were anchored in the skull. Rats were injected with $0.2 \mathrm{cc}$ Bicillin ${ }^{\mathbb{B}} \mathrm{L}$-A intramuscularly following surgery to guard against infection. Buprenorphine was available in the event that postsurgical analgesic was required. Rats were allowed 1 week of recovery, at which time they were retrained to the criterion outlined above.

\section{Cell Recording}

Once rats were running at criterion, the stereotrodes were checked daily (up to 6 days per week) for spontaneous cellular activity on the recording channels. The stereotrodes were lowered in $21.8 \mu \mathrm{m}$ increments, up to $175 \mu \mathrm{m}$ per day, or until isolated unit activity was encountered. Rats were connected to recording equipment by a preamplification headstage consisting of 5-7 high input impedance field effect transistors and a light-emitting diode. Both hemispheres were checked daily on rats with dual head plugs, whereas it was possible to check only the connected hemisphere in rats that began the experiment with one plug.

Electrophysiological data were recorded and analyzed on a DataWave Neuroscience Workstation (DataWave Technologies, Longmont, CO). Incoming signals were amplified 1,000 to 10,000 times, and filtered at $600 \mathrm{~Hz}$ (high pass) and $6 \mathrm{kHz}$ (low pass). Signals were then passed through a window discriminator that initiated a 1-ms sampling period when a signal from either channel passed a user-defined threshold. The entire waveform was recorded by DataWave's Discovery Software package. Units were isolated using an interactive cluster-cutting routine, which processed waveforms using eight spike parameters (four for each recording channe1), including the maximum and minimum voltages of the sampled waveform, and the latencies of these values from the onset of the sampling period. Following recording, additional parameters were used to further isolate waveforms of units, including a template matching algorithm that was able to further isolate unique waveform shapes. Once units were isolated, they were subjected to analysis for behavioral correlates.

The rat's position was monitored and recorded by an automatic tracking system (Dragon Tracker, model SA-2, Boulder, CO) that sampled the position of the diode at a frequency of $20 \mathrm{~Hz}$ (resolution $1.5-2.0 \mathrm{~cm}$ ). The time of each position sample and unit event was logged by the DataWave Neuroscience Workstation.

\section{Histology}

Once the electrodes were lowered through the depths of the BLA, rats were deeply anesthetized with sodium pentobarbital and perfused through the heart with a $0.9 \% \mathrm{NaCl}$ solution, followed by a $10 \%$ formalin solution. Electrodes were retracted and the brain was removed and allowed to sink in $30 \%$ sucrose formalin solution. Forty micrometer frozen sections were then sliced through the penetrated area with a cryostat. Sections were stained with Cresyl violet, and electrode tracts were histologically verified by comparing depth measurements at the time of recording with the electrode track reconstruction from serial sections of each hemisphere.

\section{Data Analysis}

Various analysis routines (DataWave Technologies, as well as courtesy of B. L. McNaughton and C. A. Barnes) were used to analyze unit characteristics and behavioral data. Mean spike amplitude, width, and rate across the entire recording session were calculated for each cell.

To determine behavioral correlates, position data were viewed off-line. Flags were entered into the data at times during which rats performed specific behaviors: reaching the ends of arms, turning on the arm ends, and initiation of inbound movement on the arms. Odd and even arms were distinguished, so that differences between high and low reward arms could be observed. Peri-event time histograms (PETHs) were created to display the change in firing in relation to behavior. These histograms plotted the firing rate of a cell $2.5 \mathrm{~s}$ prior to and after the flagged event. Significant differences were considered to occur if the rate of the cell differed by a factor of two (i.e., either an increase of $200 \%$ or a decrease of $50 \%$ ) from its mean rate during the flagged behavior.

To further analyze the effects shown to occur at the ends of arms, we calculated mean rates across successive 500 -ms bins surrounding the rat reaching the ends of arms for high and low reward arms. For the bins that showed the maximal effect size, standard errors were also computed. For a magnitude difference between the two types of arms to pass a predetermined criterion, the difference between the means for each arm type was required to exceed the sum of the standard errors for the two means (standard parametric statistics are not applicable in this case, because a cell is being compared with itself and the $n$ is never greater than one). For example, consider a cell with a maximal effect mean rate of $5 \mathrm{~Hz}$ on high reward arms and a standard error of $0.6 \mathrm{~Hz}$, and a mean rate of $4 \mathrm{~Hz}$ on low reward arms and a standard error of $0.5 \mathrm{~Hz}$. This cell would not be considered to have a differential effect because the difference between the two means $(1 \mathrm{~Hz})$ does not exceed the sum of their standard errors $(1.1 \mathrm{~Hz})$. A cell that had a mean difference of more than the sum of their standard errors on high and low reward arms was considered to have a magnitude difference effect.

To determine the onset and offset of reward effects, we compared the mean rate of the cell across 200 -ms bins for only those cells that had successfully met criterion (an increase by $200 \%$ of mean rate or decrease to $50 \%$ of mean rate). For cells that were excitatory, the beginning of the effect was defined as when the rate increased to $125 \%$ above baseline and remained above this threshold for at least two bins (to avoid classifying a transient change in firing as the onset of an effect). Offset was defined as the time after which the firing rate fell back below $125 \%$ of baseline for two 200 -ms bins. Onset and offset of inhibitory effects was similarly determined, using a threshold of $75 \%$ baseline. These times of onset and offset 
of effect were determined individually for each neuron on both high and low reward arms. Because of the potentially low resolution of this analysis, high and low reward arms were only considered to be different if their onset-offset time of effect differed by $400 \mathrm{~ms}$ or more. This analysis was done to determine whether reward-related effects could be explained by the differing size of the reward.

For the initial spatial analysis, rates of firing were compared on the outbound and inbound components of each arm (16 rates total). The specificity of each cell was determined by dividing the highest rate by the average of the 15 other rates. Furthermore, the reliability of firing across trials on the highest arm was determined as the proportion of trials in which the cell fired on the highest rate arm. As in past studies (e.g., Mizumori, Ward, \& Lavoie, 1992) that examined the location selectivity of neurons, cells that displayed a specificity score of 2.0 or greater with a reliability of at least three out of the eight behavioral trials were considered to be spatial.

Additional spatial analyses were run on cells determined to be reward related. The mean firing rate during the $500-\mathrm{ms}$ peak effect for each cell was compared between arms of each reward type (high or low). The rate of the arm with the strongest effect within its arm type was compared to that of similar reward value arms. As with the magnitude difference criterion (see above), the difference of the arm with the greatest effect was compared to the means of the other three arms. Only if this difference exceeded the sum of the standard errors for each comparison was the arm considered different from the others. This analysis was run to see if there was a spatial bias within reward arms type that may have been missed during the previous spatial investigation.

Other analyses were run on special cases. These are described in detail in the Results section.

\section{Results \\ Behavioral Results}

Rats were trained to criterion performance in an average of 12.3 days (range 10-18). For data sets that contained unit activity with correlates (see below), the mean number of errors per trial was 0.55 (or a total of 4.4 errors per eight trial session).
Rats reliably visited the high reward arms prior to low reward arms during the test phase of each trial. For recording sessions that displayed cellular correlates, a one-variable analysis of variance (ANOVA) for repeated measures was run on the number of entries to high reward arms during the rats' first four choices during the test phases of each eight-trial session. This test was significant, $F(3,102)=$ $131.098, p<.001$. Graphical representation of the data (see Figure 1) shows that this significance was due to a reliable decline of visits to high reward arms as the rat visited subsequent arms during the test phase of each trial. A complimentary rise in visits to the low reward arms was also observed.

\section{Electrophysiological Results}

Ninety-one cells were recorded from the lateral and basolateral nuclei of the amygdala ( $n=6$ rats). In congruence with previous studies recording from the lateral nucleus (Bordi \& LeDoux, 1992; Quirk, Repa, \& LeDoux, 1995), typical average firing rates of the neurons were low. Action potential activity ranged from 0.02 to $28.84 \mathrm{~Hz}$, with a mean of $2.28 \mathrm{~Hz}$ overall. The majority of cells, $61.5 \%$, displayed a firing rate of $1 \mathrm{~Hz}$ or less. The median rate was $0.56 \mathrm{~Hz}$. Spike widths ranged from 198.9 to $490.5 \mu \mathrm{s}(\mathrm{M}=295 \mu \mathrm{s})$. No differences in mean rate, width, or amplitude were observed between any of the correlates outlined below.

\section{Cell Classification}

On the basis of spatial analysis or at least a twofold increase or decrease from the mean firing rate, 34 cells of the 91 total $(37.4 \%)$ demonstrated behavioral correlates (see Table 1). This is comparable to the percentage of correlated BLA neurons recorded in prior conditioning studies (Muramoto et al., 1993; Quirk et al., 1995). Twenty-eight neurons showed correlates that centered on reward acquisition at the

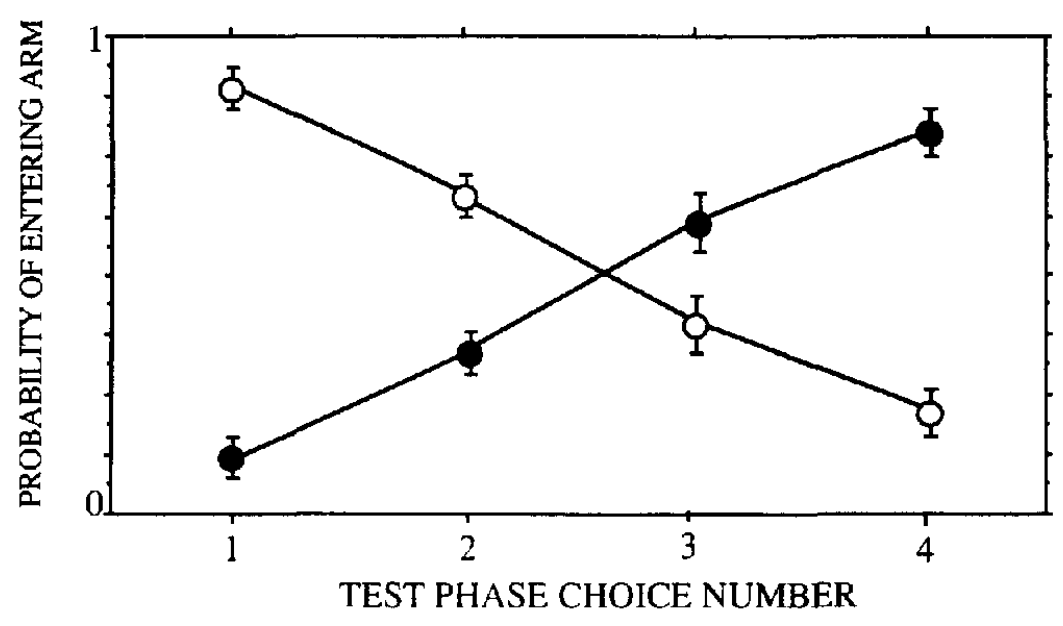

Figure 1. Behavioral demonstration of the reward arm type that rats visited during the first four choices of the test phase for each trial. Shown is the probability of the rats entering a high reward arm (open circles) or low reward arm (closed circles) as the test phase progressed. Rats began the test phase of the each trial by visiting arms with higher reward magnitude, and subsequently retrieved reward from arms with less chocolate milk. 
Table 1

General Breakdown of Basolateral Nuclei

of the Amygdala (BLA) Correlates

\begin{tabular}{lc}
\hline \multicolumn{1}{c}{ Type of correlate } & Number observed \\
\hline Auditory neurons & 1 \\
Spatial neurons & 7 \\
Reward-related neurons & \\
$\quad$ Inhibition neurons & 10 \\
$\quad$ Inhibition at encounter & 7 \\
$\quad$ Anticipatory inhibition & \\
Burst neurons & 1 \\
$\quad$ Burst at encounter & 5 \\
$\quad$ Anticipatory burst & \\
Biphasic neurons & 3 \\
$\quad$ Excitatory-inhibitory & 2 \\
Inhibitory-excitatory & 2 \\
Movement neurons & 34 \\
Total cells with correlates & 91 \\
Total cells recorded &
\end{tabular}

Note. The reward correlate group is subdivided into each of its classifications, and the number of cells recorded for each is displayed. Four cells were determined to be in both the reward and spatial categories; thus, the total number of correlated cells is less than the simple sum of all the correlate categories. The detection of an auditory neuron was the result of a strikingly obvious correlate. It is likely that more such neurons would be found if we had tested firing to pure tones.

end of the arms. To determine if the effects were related to the actual encounter of reward or to the cessation of movement, flags were inserted into the data file off-line at times when the rat stopped on the center platform, where reward was never received. On the basis of this analysis, two cells that displayed similar patterns during cessation of movement on the center platform as at the end of arms were determined not to be reward sensitive, and were considered general movement cells.

One cell fired vigorously to various auditory stimuli (i.e., whistles, keys jingling, and the noise made by maze arms as they were raised and lowered). It should be noted, however, that this experiment did not involve explicitly testing responses to neurons to pure tones, as has been done in previous studies. It is likely that such testing would result in a greater number of auditory responsive neurons. However, the presence of this cell remains consistent with work by others studying the basis of auditory fear conditioning (Quirk et al., 1995).

Seven cells met the predefined spatial criteria. Reward and spatial correlate cells are discussed further.

\section{Reward-Related Correlates}

Encounter and anticipatory effects. Reward cells were classified by the pattern of activity that was observed near the time of reward encounter. Seventeen cells $(18.7 \%$ of total cells recorded) showed an exclusively inhibitory pattern, which occurred prior to and/or immediately following the acquisition of the reward at the end of the arms. These were subsequently classified as two inhibitory categories: inhibition at encounter neurons and anticipatory inhibition neurons. Ten inhibition at encounter cells $(11 \%)$ inhibited within $200 \mathrm{~ms}$ of the acquisition of chocolate milk (see Figure 2A). Seven anticipatory inhibition neurons $(7.7 \%)$ inhibited during the rats' approach behavior more than 200 $\mathrm{ms}$ prior to the acquisition of chocolate milk (see Figure 2B). Five out of seven of these anticipatory neurons remained inhibited into the consummatory phase of the behavior.

Six cells $(6.6 \%)$ showed an exclusively excitatory effect. Because of the brief excitatory responses of these cells, they were classified as burst neurons (see Figures $3 \mathrm{~A}$ and $3 \mathrm{~B}$ ). One cell of this type showed a significant rise in firing prior to reward acquisition, which dissipated within $600 \mathrm{~ms}$ after reward encounter. Three burst neurons demonstrated maximal activity centered at Time 0 , when the rat encountered the chocolate milk. Two other cells showed similar peaks in activity that were centered within $1 \mathrm{~s}$ after reward encounter. Five of the six ( $83.3 \%$ ) burst neurons began their rise to a peak prior to the reward encounter (anticipatory burst neurons), whereas one fired only after reward acquisition (burst at encounter neuron).

The final class of reward-related neurons had a vacillatory effect centered generally on the acquisition of reward (see Figures $4 \mathrm{~A}$ and $4 \mathrm{~B}$ ). These five cells ( $5.5 \%$ ) were considered to be biphasic. Three exhibited a significant excitatory rise during approach behavior, followed by a significant inhibition that occurred at reward encounter (excitatory-inhibitory biphasic). Two other cells showed the opposite pattern, with a significant decrease during early approach behavior that alternated to an anticipatory rise in activity that peaked just after reward onset (inhibitory-excitatory biphasic). By their nature, all biphasic neurons were considered anticipatory.

Thus, of the 28 neurons that showed activity correlated to the acquisition of reward, 17 (60.7\% of reward-correlated cells) displayed changes that anticipated the onset of reward by more than $200 \mathrm{~ms}$. The remaining 11 cells changed their firing rate only after encountering the reward.

Magnitude differences. Comparisons of neural activity on high versus low reward arms determined that 15 of the 28 neurons that were reward related displayed differential responding during the $500 \mathrm{~ms}$ in which the cell displayed its maximal effect (see Figure 5; see also Figure 2B). For cells that exhibited both anticipatory and consummatory effects, this analysis was run on both phases of behavior. This examination determined that 4 of 7 inhibition at encounter, 5 of 10 anticipatory inhibition, 3 of 5 anticipatory burst, and 3 of 5 biphasic neurons showed a magnitude difference between high and low reward arms during at least one phase of the behavior. Table 2 outlines the cell types that demonstrated these differences and describes the temporal characteristics of the effect for each arm type. All but four of the cells that were determined to have magnitude differences showed a consistently greater effect on the high reward arms when compared to low reward arms.

Differences in the time of onset of the differential reward effects were also observed in some cells. Nonanticipatory neurons had onset times on both high and low reward arms that were generally centered at the time of chocolate milk acquisition. Of the anticipatory cells, 11 demonstrated an onset of effect that was at least $400 \mathrm{~ms}$ apart on high versus low reward arms. These cells consisted of 4 out of 5 biphasic 
A

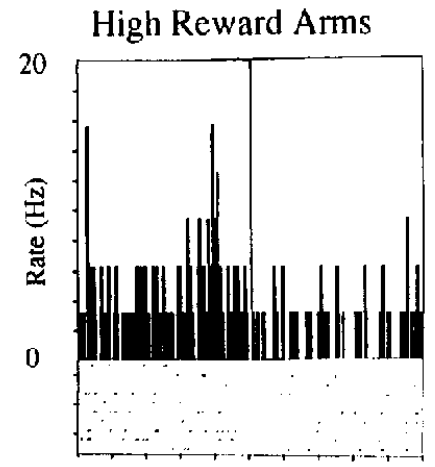

B

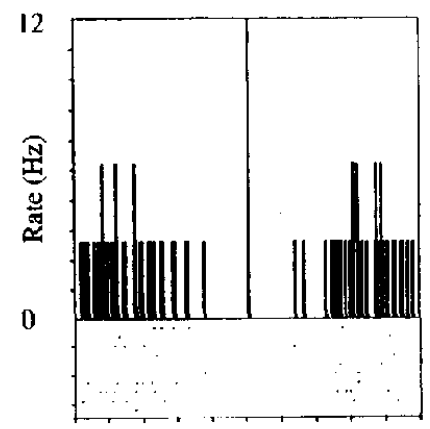

$-2.5$
Low Reward Arms
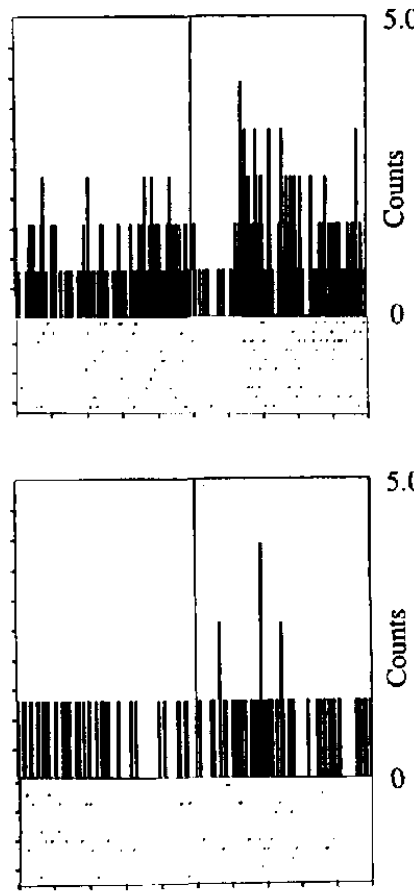

$2.5-2.5$

me $(\sec )$
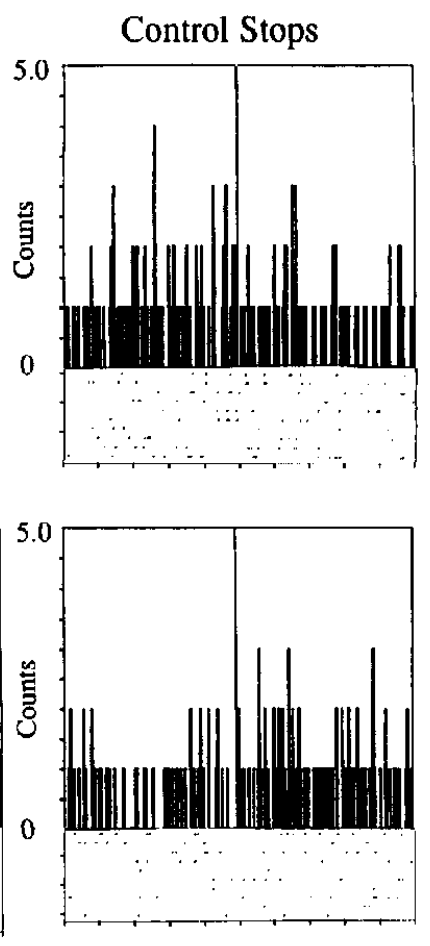

Time $(\mathrm{sec})$

Figure 2. Examples of the two classes of inhibitory neurons encountered. Each peri-event time histogram (PETH) is centered on the time that the rat encountered the reward at the end of each arm. Raster plots beneath each PETH show the spiking activity for 10 encounters. A: Inhibition at encounter neurons demonstrated a decline in firing rate by at least $50 \%$ following the encounter with the chocolate milk. B: Anticipatory inhibition neurons showed a similar decrease in firing rate during the approach phase of the behavior. Note that in this neuron, the inhibition continues into the consummatory phase only on high reward arms. For both neurons, the effect at the ends of the arms was compared to the firing pattern when the rats stopped on the center platform (control stops). Note the lack of effect for these control conditions, suggesting that these neurons are not movement related. Histograms for the control stop condition utilize counts (number of spikes observed) rather than rate in hertz (number of counts per second) due to the lower number of samples observed for this condition relative to stopping at the end of the arms.

neurons, 4 of 5 anticipatory burst neurons, and 3 of 10 anticipatory inhibition neurons that showed this incongruity of effect onset. Of these, 7 neurons had an earlier effect onset for low reward arms ( 3 biphasic, 1 burst at encounter, and 3 anticipatory inhibition). This suggests that these neurons may not fire merely on the basis of the sight or smell of the chocolate milk, because if this were the case the neurons would fire to the more visible larger reward first. Additional evidence that anticipatory cells may not be entirely dependent on visual information was provided by an inhibitoryexcitatory biphasic neuron that underwent a light-dark manipulation. On a second day of testing with this unit, the rat underwent eight maze trials. The first four trials were in the normal lighted condition, and the second block of four was run in darkness. The absence of the light did not attenuate either the anticipatory inhibition of this cell or its subsequent excitation (see Figure 6). On the contrary, the absence of light augmented the inhibition observed prior to reward encounter and increased the amount of time that the postencounter effect was observed. This suggests that although the sight of the reward itself was not critical for the firing of this neuron, visual input may modulate the firing of these neurons. However, due to a mechanical failure, another block of trials testing a return to light condition was not run during this dataset. As a result, it is impossible to determine whether the clearer nature of the effect during darkness was related to the absence of light or to a sharpening of the neural response as the trials progressed. This biphasic neuron also underwent a test condition on a third day in which reward was replaced with water randomly on two of the eight arms for each trial. Both the anticipatory and postencounter responses of this cell remained, even on no-reward arms.

All cells that showed reward encounter effects, by definition, had a change in firing rate that lasted into the consummatory phase of the rat's behavior. All but two anticipatory cells also showed an effect that continued beyond reward acquisition. In most cases ( 25 out of 28 ), the 

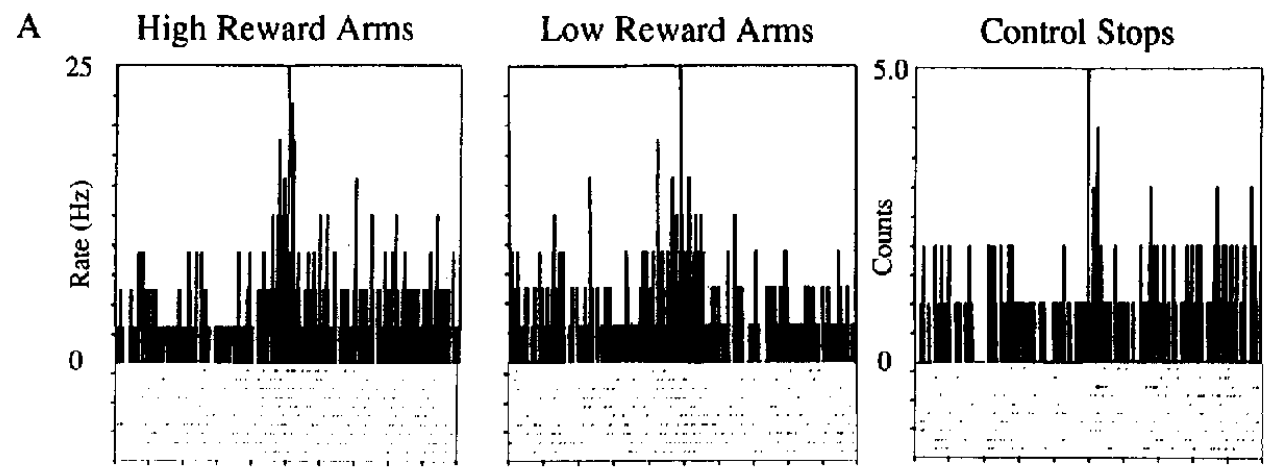

B
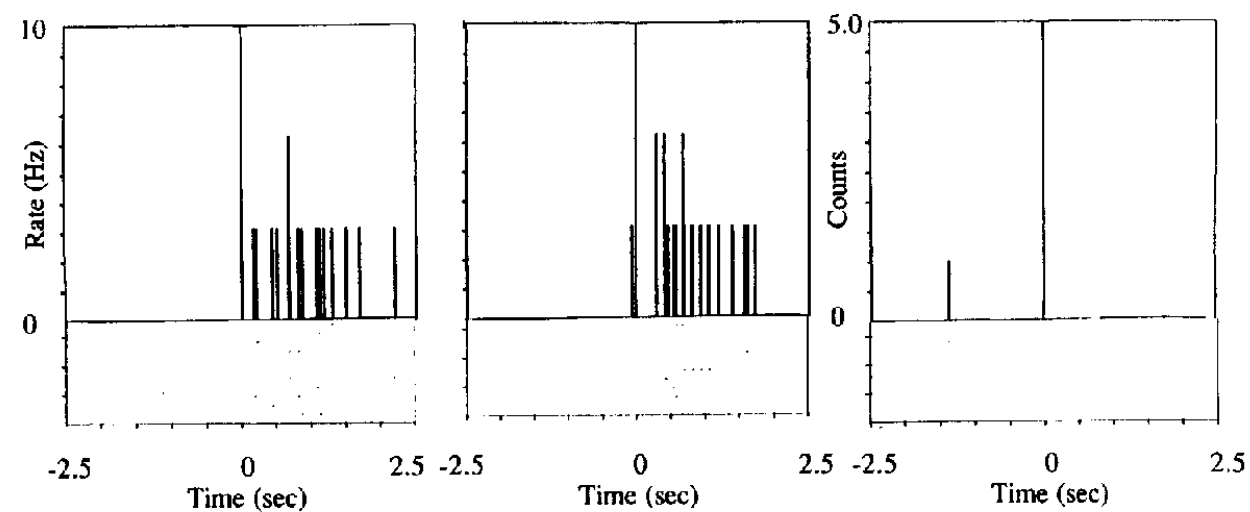

Figure 3. Examples of burst neurons, in which the firing rate of the neuron doubled relative to reward acquisition. A: an anticipatory burst neuron. Although the peak of the effect is centered on the time of acquisition of the reward, there is an anticipatory rise that immediately preceded the encounter. B: a burst at encounter neuron. This neuron showed a burst of activity immediately after reward encounter.

effect offset was equal to or more than $400 \mathrm{~ms}$ divergent on high versus low reward arms. To determine if a systematic difference of effect occurred on high versus low reward arms, we ran a regression between offset times on both types of arms for cells that showed an effect that continued into the consummatory phase. A significant correlation of .481 was observed, $F(1,24)=4.764, p<.05$, with a slope of .21 , suggesting that the latency of effect offset was, on average, five times greater for high reward arms when compared to low reward arms.

Dependency on the presence of reward. The replacement of chocolate milk reward with water in the case of the one biphasic cell tested (see description above) revealed no significant attenuation of the neuron's response upon reaching the arm ends. To further determine whether effects observed were dependent on the reward being physically present at the ends of the arms, data sets in which the rats made more than five errors (i.e., when the rat proceeded down arms that they had previously visited) were flagged for additional analyses. Three inhibition at encounter cells, five anticipatory inhibition cells, and one biphasic neuron qualified for this analysis.

PETHs centered around reaching the end of the error arms were generated (see Figure 7). Of the inhibition at encounter cells, only one showed a weak resemblance to the pattern displayed at normal reward acquisition, suggesting that the effect at reward onset may be largely driven by the presence of the reward itself. Two of the five anticipatory inhibition neurons also showed little resemblance to the normal acquisition pattern. However, three of these neurons showed distinct depression that occurred prior to reaching the end of the arm (see Figure 7A). This pattern was consistent with their firing rate on rewarded arms and may constitute an anticipatory effect that is not dependent on the presence of the reward. Similarly to the inhibition at encounter cells, however, two of these anticipatory inhibition cells that normally had effects that persisted into consummatory behavior showed no lasting postencounter effect when not confronted with reward. A biphasic cell (not the same one as discussed with manipulations above), in contrast, displayed a similar response on error arms as on normally baited arms (see Figure 7B).

Further evidence suggests that neural changes during the consummatory phase of behavior may be directly dependent on either the drinking behavior itself or the sensory consequences of imbibing the chocolate milk. One cell, which showed a significant effect during consumption, was subjected to a second day of testing. Three blocks of four trials each were presented to the rat. The first and third blocks were the normal condition. During the second block, the arms associated with a particular reward magnitude were reversed (i.e., the rat encountered high reward where low 
A

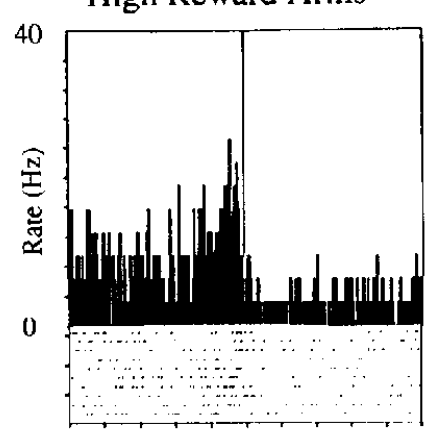

B

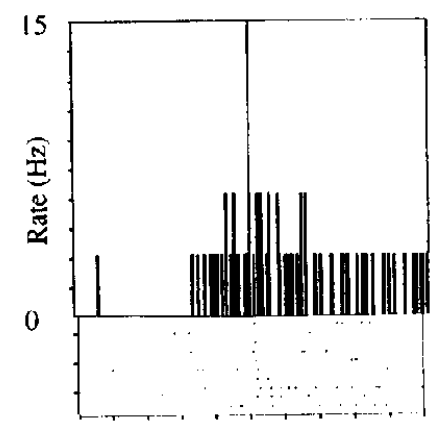

$-2.5$

High Reward Arms
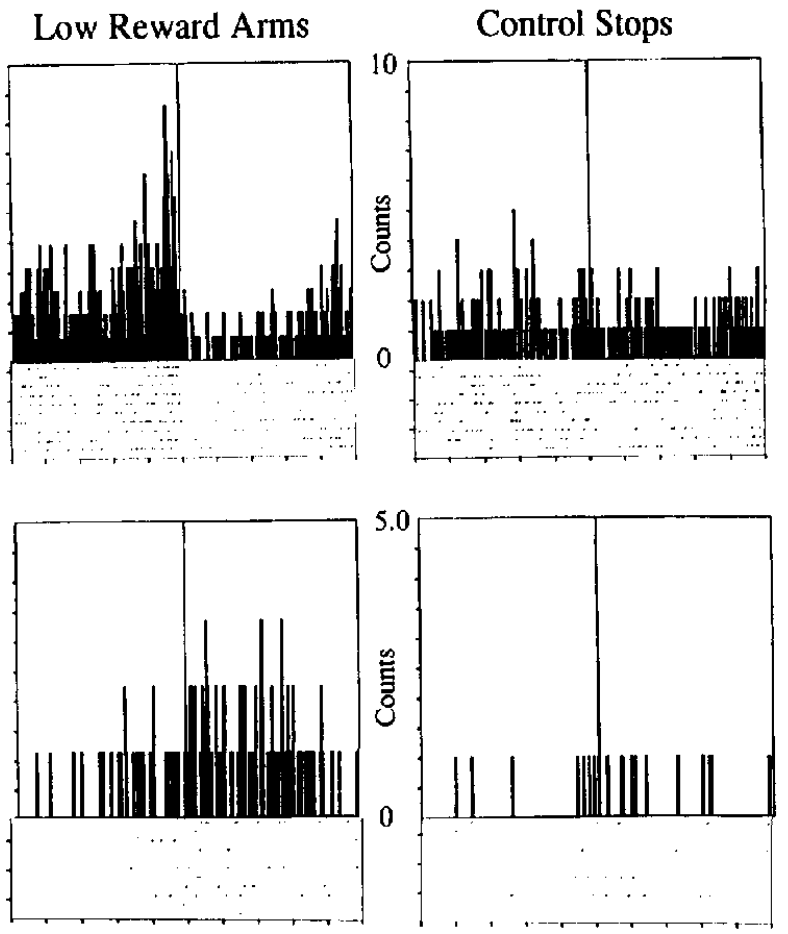

Time (sec)
$2.5-2.5$

$-2.5$ $\begin{array}{lll}2.5 & -2.5\end{array}$

Time (sec)
0
Time $(\mathrm{sec})$
2.5

Figure 4. Examples of biphasic neurons. A: an excitatory-inhibitory biphasic neuron. The rate of firing of this cell more than doubled during the approach phase of the behavior, and then inhibited to less than half of the mean rate of the cell at reward encounter. B: an inhibitory-excitatory biphasic neuron. During approach, this neuron was inhibited, and showed an excitatory burst during the consummatory phase.

reward was normally found, and vice versa). The long latency that was associated with the high reward arms followed the reward rather than staying on the previously associated arms, suggesting that it was the ingesting of the reward that was the critical component for this cell (see Figure 8).

\section{Spatial Correlates}

In addition to the analyses described above, all cells recorded from the BLA were subjected to a spatial analysis similar to that used to evaluate spatial properties of place cells recorded from other brain areas. Using the general criterion discussed in the methodology (specificity of at least 2.0 , reliability of $3 / 8$ or greater), seven neurons displayed spatial properties. Spatial reliability did not exceed $3 / 8$ in any of these cases. The three most spatial cells are presented in Figure 9. In general, the spatial acuity of these neurons was much less distinct than previously reported from the HPC or the nucleus accumbens. Four of these neurons were also determined to be reward-related. To examine whether the fields of the spatial neurons were directional, we compared outbound firing rates to inbound firing rates on the maze arm that showed the specificity. Cells that had rates in one direction that were more than twice the rate in the other direction were considered directional. Four spatial cells met these criteria; two showed an inbound preference and two an outbound preference. Both of the outbound directional units were also classified as reward related, and therefore it was impossible to tell whether the directionality was a result of a spatially related effect or the reward-related effect, or both. However, place fields did not show a strong preference to occur on one type of rewarded arm. Three of the seven fields occurred on low reward arms, and four of seven were on high reward arms, suggesting that the spatial nature of these neurons is to some degree independent of the reward representations observed (see above).

It was also of interest to determine if reward-related cells displayed arm biases within each type of reward arm (high or low). To accomplish this, we compared arms that showed the greatest effect on high and low reward arms to the other three arms of its type. Only two cells (one inhibitory and one biphasic) showed preference of one arm over the other arms. However, these effects were weak, with less than a $50 \%$ change in firing rate distinguishing the "best" arm from the other arms of its type. Twenty-six out of twenty-eight (92.9\%) reward neurons did not show arm biases among like arm types.

\section{Study Versus Test Phase Analysis}

To determine if there was a difference in the pattern of firing between the study phase and test phase of each trial, we conducted a mixed design repeated-measures ANOVA 
A

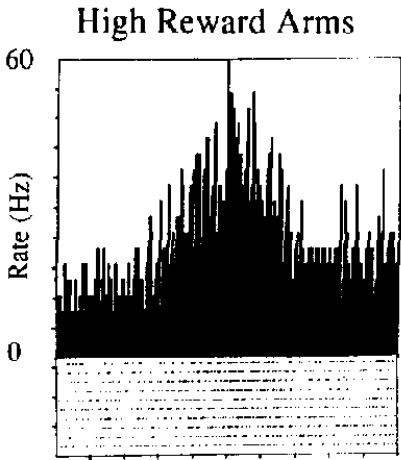

B

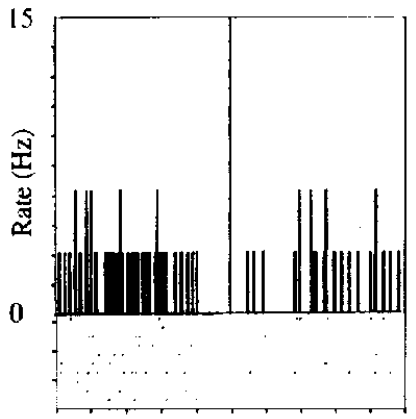

$-2.5$
Low Reward Arms
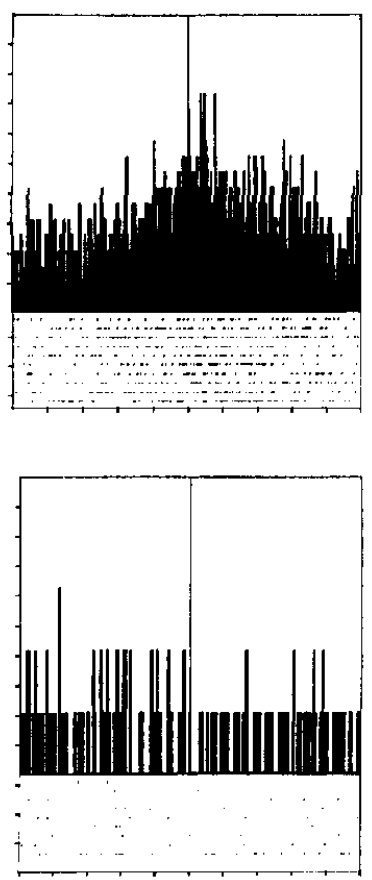

Time (sec)
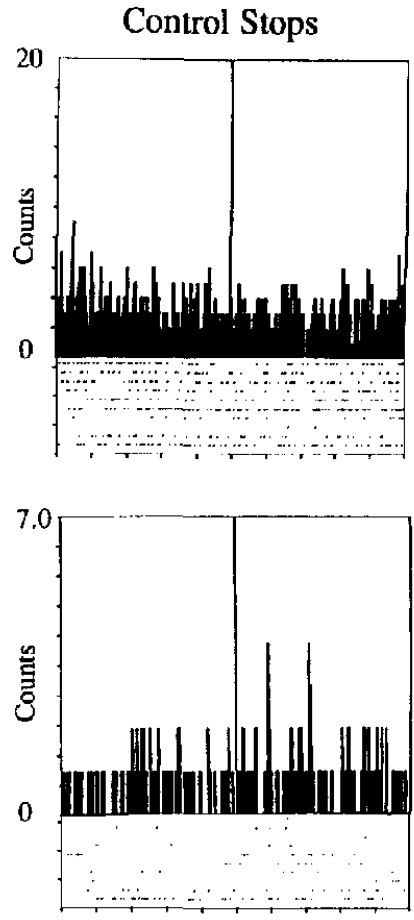

$2.5-2.5$

Figure 5. Two cells that showed differential firing on high and low reward arms. A: This anticipatory burst neuron showed a higher rate of firing when the rat visited high reward arms. B: an anticipatory inhibition neuron, which demonstrated a decrease in firing rate only on high reward arms. The presence of neurons of these types suggests that BLA neurons may encode differences in reward magnitude.

on the rates for each cell during the time of maximal effect (see above) for each recording session. Each type of reward neuron (inhibition, burst, and biphasic) was evaluated on both high and low reward arms. There was no significant difference of the repeated measure (study vs. test phase) on high reward arms, $F(1,39)=2.213, p>.1$, or low reward arms, $F(1,39)=0.096, p>$.1. Furthermore, no interaction

Table 2

Summary of Reward-Related Neurons That

Displayed Magnitude Differences

\begin{tabular}{|c|c|c|}
\hline Neuron type & Number & $\begin{array}{l}\text { Characteristics of } \\
\text { magnitude difference }\end{array}$ \\
\hline Inhibition at encounter & 4 & $\begin{array}{l}\text { All differences followed reward } \\
\text { encounter. }\end{array}$ \\
\hline Anticipatory inhibition & 5 & $\begin{array}{l}\text { All cells showed differences } \\
\text { during approach. Three cells } \\
\text { demonstrated differences after } \\
\text { encounter as well. }\end{array}$ \\
\hline Burst at encounter & 0 & \\
\hline Anticipatory burst & 3 & $\begin{array}{l}\text { Difference centered on Time } 0 \\
\text { for two cells. One cell showed } \\
\text { difference during encounter. }\end{array}$ \\
\hline Biphasic & 3 & $\begin{array}{l}\text { All cells showed differences fol- } \\
\text { lowing cncounter. Onc cell } \\
\text { showed differences during } \\
\text { approach as well. }\end{array}$ \\
\hline
\end{tabular}

Total

15 effect was seen between the repeated measure and cell type: $F(2,39)=2.064, p>.1$, for high reward arms; $F(2,39)=$ $0.437, p>.1$, for low reward arms. This analysis demonstrates that none of the three classifications of reward-related neurons showed differential firing based on the phase of the task (see Figure 10).

\section{Distribution of Correlates}

Correlates were spread evenly across the structure with two exceptions (see Figure 11). Four out of five (80\%) burst at encounter neurons were located in the ventral areas of the BLA. In contrast, all biphasic neurons were located in the rostral dorsal extent of the BLA. Anticipatory inhibition, inhibition at encounter, and spatially correlated cells were found throughout the BLA nuclei.

\section{Discussion}

The goal of this experiment was to evaluate the possibility that the BLA might contribute reward-related information important for adaptive spatial behavior. This was accomplished by characterizing the neuronal activity of BLA neurons while rats performed an eight arm radial maze memory task with differential reward. Cells were observed that increased or decreased their firing in response to reward acquisition, or in anticipation of reward encounter. The 
A
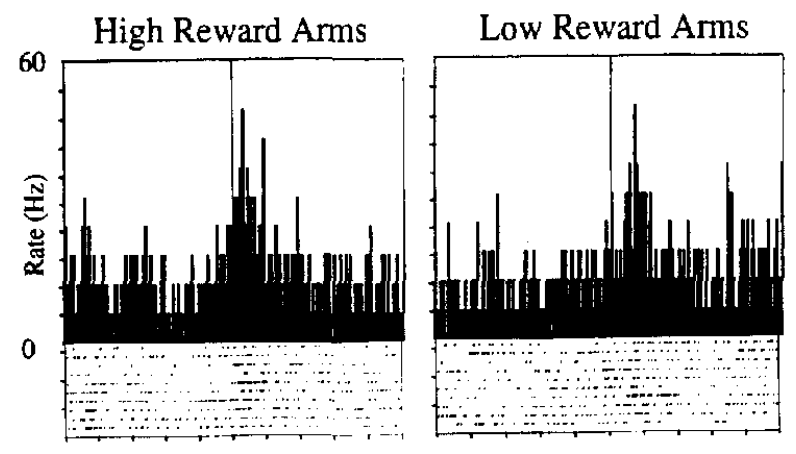

B

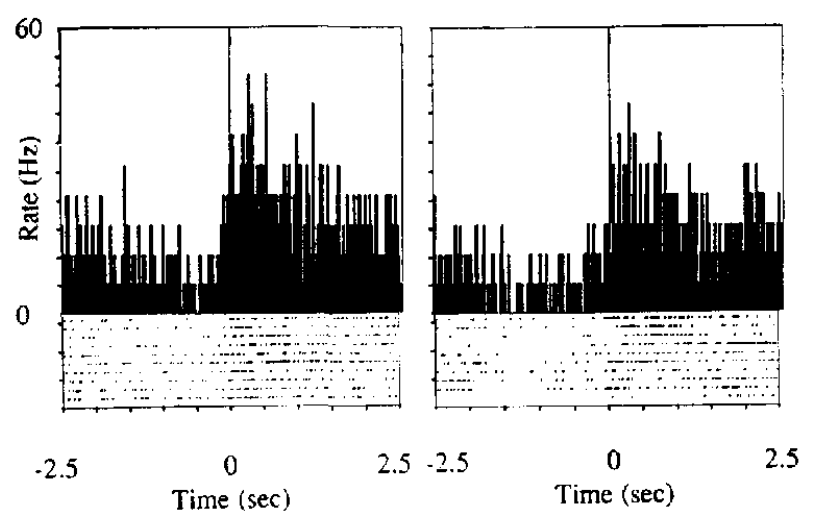

Figure 6. An inhibitory-excitatory biphasic cell (A) does not demonstrate a decline in the nature of the firing of the neuron even when lights were switched off (B). This suggests that the sight of the reward is not the sole driving input for these neurons. In this case, the absence of light augmented the inhibition observed prior to reward encounter, and increased the amount of time that the postencounter effect was observed. This suggests that although the sight of the reward itself was not critical for the firing of this neuron, visual input may modulate the firing of these neurons.

presence of cell activity that was reward-sensitive upheld the hypothesis that these neurons may pass on reward-related information to the medial VS. It should be noted, however, that we are not suggesting that the BLA is the only system that is responsible for providing the medial VS with reward-related information. Certainly, such regions as the ventral tegmentum and medial prefrontal cortex also have the potential to play important roles.

Postencounter effects of the reward-related cells as a whole suggested that it was the presence of the reward itself that drove this phase of the effect. A strong correlation comparing time of offset of the consummatory effect showed that, on average, changes in firing rate lasted five times longer on the high reward arms when compared to the low reward arms. This is consistent with the relative amount of time that the rats likely spent drinking the chocolate milk. Altering the location of the reward during the testing of one neuron demonstrated that postencounter enhancement of inhibition on high reward arms followed the relocation of the reward (see Figure 8). Analysis of neural firing when rats revisited arms that they had already retrieved chocolate milk from showed an absence of the postencounter effect in most cases.
Such data suggest that the sensory or motor consequences of drinking may play an important role in the coding of postencounter neurons during this navigational task. Activity of amygdala neurons to food or liquid reward has been documented previously in the monkey (Nishijo et al., 1988b; Sanghera et al., 1979) and the rat (Muramoto et al., 1993) during sensory discrimination, and it is known that the amygdala receives extensive inputs from olfactory and gustatory sensory areas (for reviews, see Amaral, Price, Pitkanen, \& Carmichael, 1992; De Olmos, Alheid, \& Beltramino, 1985; see also Luskin \& Price, 1983; Ottersen, 1982; Turner \& Herkenham, 1991).

Other reward-related cells showed an onset of effect that occurred prior to reward encounter (anticipatory cells). In contrast to the reward-dependent nature of the postencounter neurons, three of five anticipatory inhibition cells that were tested on error arms showed similar inhibition when chocolate milk was not present at the arm ends (see Figure 7A). Similarly, two biphasic cells maintained a change in firing rate prior to and following reaching arm ends even when the reward was removed. These findings, together with the observation of anticipatory neurons that showed an earlier effect onset on low reward arms, suggest that anticipatory reward cells are not merely driven by olfactory or visual features of the reward per se. The observation of neurons that displayed differential firing on high versus low reward arms leads to the suggestion that the BLA may encode anticipatory information and features relating to the magnitude of the reward.

The results of this experiment offer insight into the nature of stimulus-reward associations made within the BLA. In this task, no single extramaze cue could be associated with a particular reward magnitude, because high and low rewards were placed at four different locations on the maze, each having an essentially unique array of stimulus cues. The majority of BLA neurons recorded in this experiment did not show a tendency to fire only at the locations of particular cues. Those neurons that differentiated between high and low reward arms did so across all arms, suggesting that neurons within the BLA are able to associate different cue arrays with similar reward magnitudes. This provides an extension from previous research using classical conditioning techniques. Muramoto et al. (1993) found that BLA neurons were more likely than centromedial amygdala cells to differentiate between cues that distinguished between two rewards of the same positive valence. The current experiment further demonstrates BLA complexity by showing that the BLA is able to incorporate more than one cue or cue array into the same reward representation. Thus, anticipatory reward cells may be driven by cues that have been paired previously with similar magnitude rewards. The BLA is known to receive extensive afferent connections from sensory regions (for reviews, see Amaral et al., 1992; Gloor, 1997) that, the current and previous data suggest, are able to be paired with rewarding or aversive stimuli. In the case of stimulus-reward associations, information concerning the rewarding nature of a positive reinforcer may be relayed to the amygdala via its connections with gustatory systems (Luskin \& Price, 1983; Turner \& Herkenham, 1991), the 
A

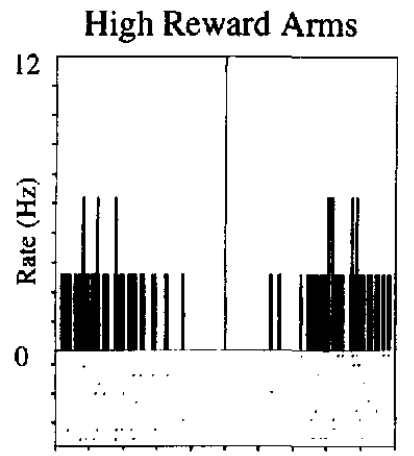

B

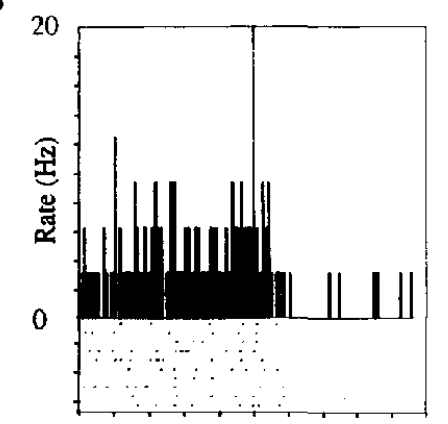

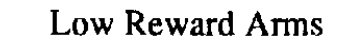
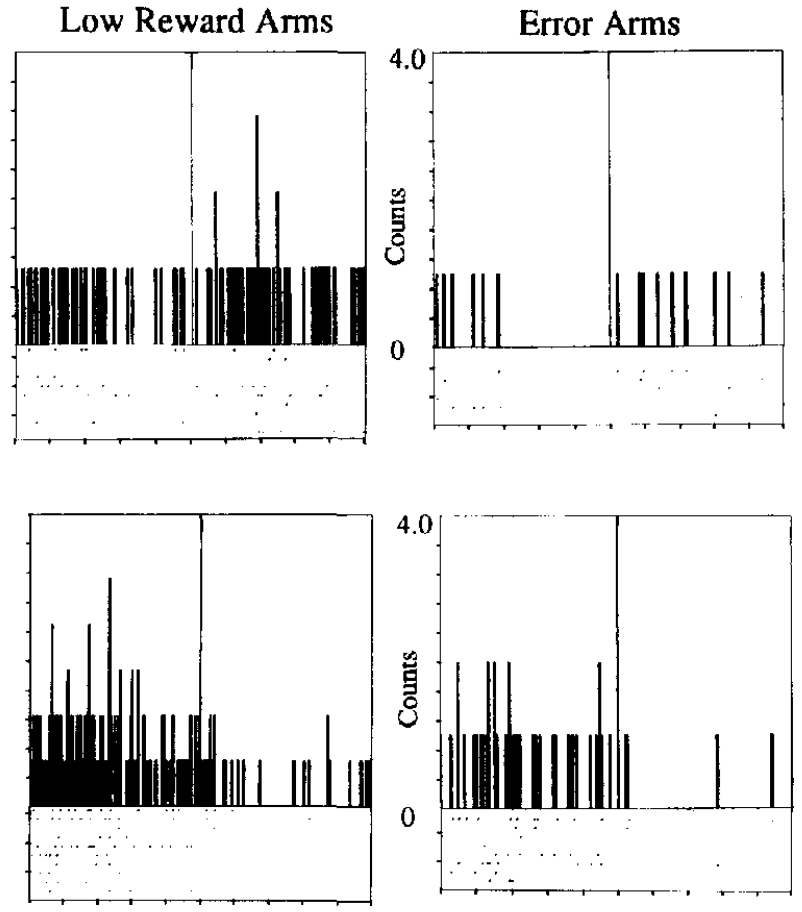

$2.5-2.5$

$2.5-2.5$

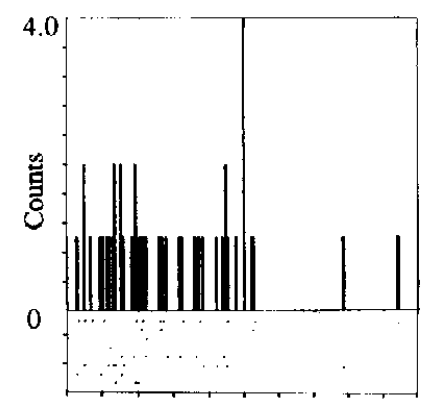

$\stackrel{0}{\text { Time }(\mathrm{sec})}$

$\begin{array}{cc}-2.5 & 0 \\ & \text { Time }(\mathrm{sec})\end{array}$

Figure 7. Error arm analysis for two different neurons. Firing rates for reward-related neurons during acquisition of reward were compared to the firing of the neuron when the rat made errors to arms that had been visited previously during the trial. A: an anticipatory inhibition neuron, which showed similar firing during the approach phase on error arms as on rewarded arms. B: an excitatory-inhibitory biphasic neuron, which showed similar responses on both rewarded and unrewarded arms. These two cell types suggest that the anticipatory nature of these reward-related cells are not directly dependent on the visual or olfactory presence of the chocolate milk.

ventral tegmentum (Swanson, 1982), or the prefrontal cortex (Sesack, Deutch, Roth, \& Bunney, 1989), all of which have been implicated in mediating either natural or drug-related rewards.

Although seven cells were observed that had a spatial correlate, the place fields observed were not as specific as those of the HPC, or even the VS. It is unlikely that the output of the BLA is conveying a robust spatial signal. Indeed, past studies that have examined the role of the amygdala in spatial contexts have not suggested that the amygdala is important for the working-memory aspects of navigational behavior (McDonald \& White, 1993). Rather, recent evidence has shown that it is HPC connections to the nucleus accumbens and prefrontal cortex that may play a large role in the neural mechanisms underlying the working memory required for remembering where one has been in space (Floresco et al., 1997). However, spatial paradigms, such as the conditioned place preference task, have shown effects of amygdala lesions on spatial behavior that is dependent on knowledge of reward magnitude (Everitt et al., 1991; McDonald \& White, 1993). Furthermore, lesions and lidocaine inactivation of the amygdala have been shown to have a detrimental effect in paradigms that test memory for the size of reward (Kesner \& Williams, 1995; Salinas,
Packard, \& McGaugh, 1993). The observation in the current study that there was no difference in firing of reward-related neurons between the study and test phases of the maze task also suggests that the mnemonic role of the amygdala is independent of spatial working memory. Instead, the presence of anticipatory reward neurons and cells that fired differentially between high and low reward amounts implies that the amygdala may provide information concerning differential reward magnitudes to the working memory systems underlying navigation. In the absence of this kind of reward contingency, the amygdala may not be a critical brain region involved in spatial learning. As a result, BLA lesions would not be expected to impair accuracy during performance of the standard spatial working memory task (McDonald \& White, 1993).

A majority of projection cells in the BLA have been shown to discharge in burst or multiple spike patterns (Yajeya et al., 1997), which is consistent with the pattern of firing we observed for the reward-related neurons. Therefore, it is likely that the reward-related information is a significant portion of the BLA efferent message in this task. Consideration of the anatomical distribution of the observed correlates may reveal insight into the organization of BLA efferent messages. Although many of the BLA correlates 

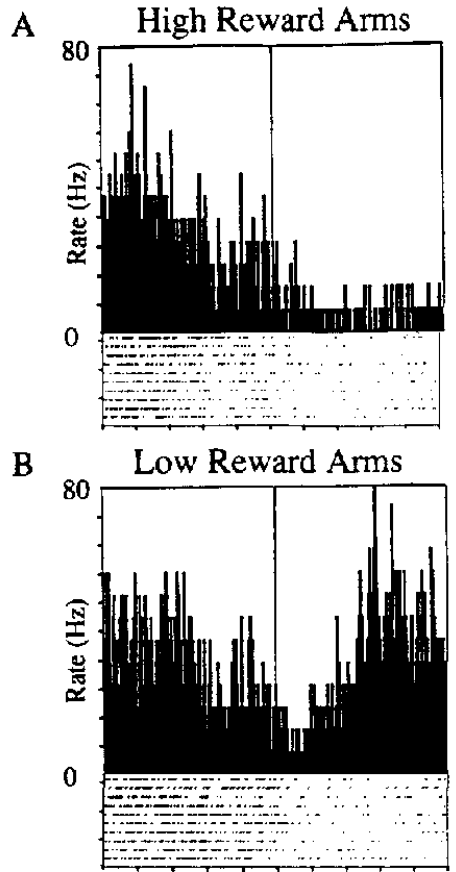

C

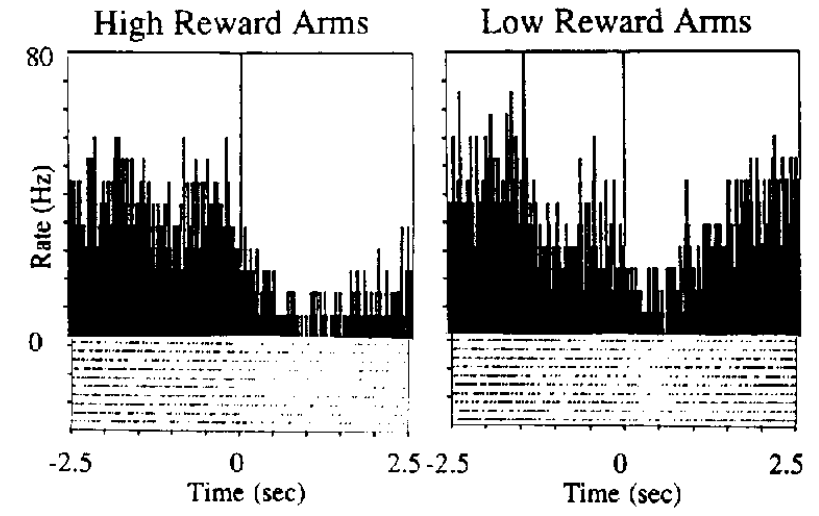

Figure 8. An example of the reward-dependent nature of the consummatory effect in an inhibition neuron. The duration of inhibition was greatest on the high reward arms (A). When the level of reward was switched between high and low reward arms on the maze, the effect followed the reward (B). When the rewards were switched back to their usual arms, the greater response of the neuron again follows the reward $(\mathrm{C})$.

found in the present study were dispersed relatively diffusely throughout the structure (see Figure 11), there were two classifications of neurons that appeared to be limited to specific regions of the BLA complex. Four of five burst neurons were found in the ventral regions, and five of five biphasic neurons were located in the anterior dorsal region. It is possible that this is a consequence of a low sample of these cell types; however, it is also possible that this represents an anatomical distinction in the types of information relayed by the BLA nuclei. Anterior dorsal regions of the BLA project to caudal regions of the extended amygdala; the posterior and ventral BLA have stronger projections to the VS, including the nucleus accumbens (Kelly et al., 1982; McDonald, 1991). Therefore, the burst cells may have a direct influence on downstream activity within the medial VS, whereas biphasic neurons may impact the VS via connections within the extended amygdala. The discovery that many of the reward-related neurons are distributed across the entirety of the BLA suggests that their signals are being sent to both arousal structures mediated by an anterior BLA-centromedial amygdala connection and to the VS via more posterior BLA regions.

Recordings from the medial VS on a radial maze task similar to the one used in the present study demonstrated both spatial and reward-related correlates (Lavoie \& Mizumori, 1994). A comparison of the correlates within the BLA shows a striking similarity with the types of reward neurons that were found within the VS. Eleven neurons were recorded from the VS that, similarly to BLA neurons, doubled or halved their firing rates at reward encounter. This effect was also shown to be dependent on the presence of reward. Seven of the medial VS cells showed an anticipatory effect, as did several cells in the current study. Two cells showed differences in effect on high versus low reward arms. These similarities provide further evidence that the BLA transmits important reward-based information to the VS. Such information may then converge with inputs from spatial memory structures before being passed on to motor output structures.

Both the BLA and the HPC project to the medial VS, a region that has been suggested to be the interface between the limbic system and motor output (Mogenson, Brudzynski, Wu, Yang, \& Yim, 1993). The amygdala and HPC have largely been studied as independent units, but it is important to note that neither structure is autonomous from the other. There are known connections from the BLA to the HPC in the rat (Witter, Groenewegen, Lopes Da Silva \& Lohman, 1989) and the monkey (for a review, see Amaral et al., 1992). Such connectivity may, in part, be responsible for the observation of "approach-consummate" and "appetitive" neurons observed in rat HPC by Ranck (1973), as well as HPC "goal approach" neurons reported by Eichenbaum, Kuperstein, Fagan, and Nagode (1987). There are also reciprocal projections from the hippocampal complex to the amygdala. The most notable of these are the projections from the ventral subiculum and entorhinal cortex. The primary terminal fields of each projection are the medial posterior BLA (basomedial nucleus) and anterior BLA, respectively (Canteras \& Swanson, 1992; Witter et al., 1989). Such connectivity may allow for a contextual signal to reach the BLA, to be associated with rewarding or aversive events in a similar manner to the pairing of discrete auditory or visual stimuli. HPC stimulation has been shown to alter the neural activity of cells throughout the basolateral extent of the amygdala in the rat (Mello, Tan, \& Finch, 1992a, 1992b). Additionally, high-frequency stimulation of the ventral angular bundle (which contains the primary efferents from the HPC to the amygdala) has supported $N$-methyl-D-aspartate-dependent long-term potentiation within the BLA, suggesting that HPC input to this region may be able to support experience-dependent plasticity (Maren \& Fanselow, 1995). This pathway also appears to be 
A

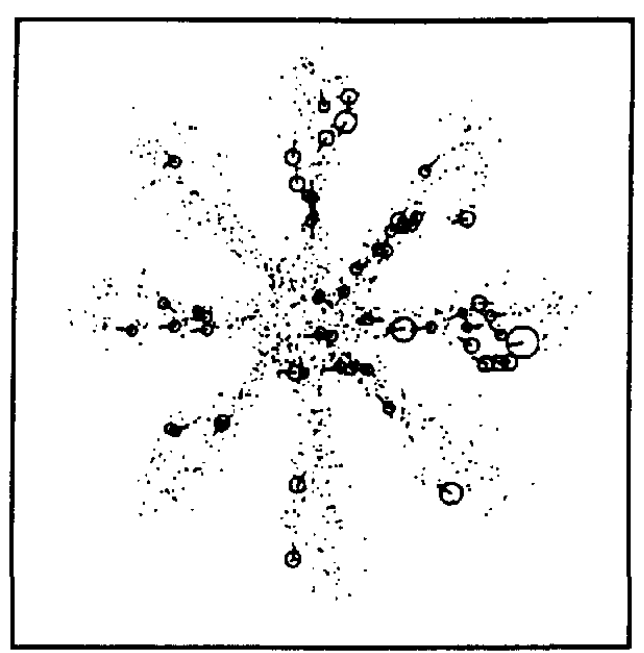

B

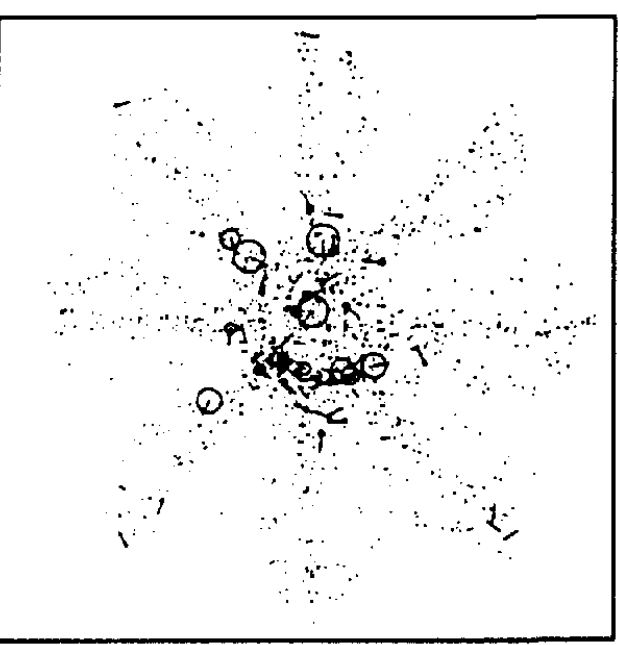

C

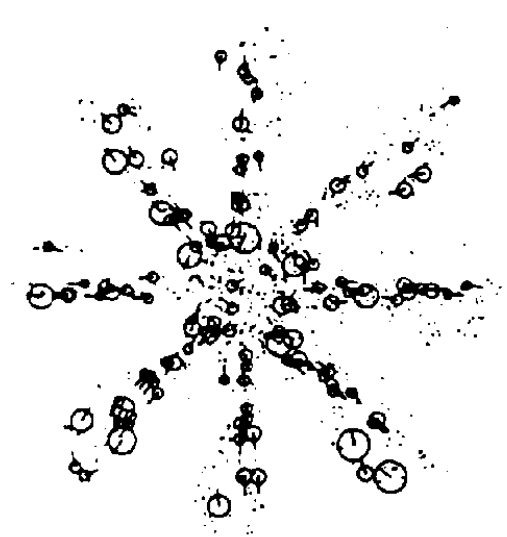

A

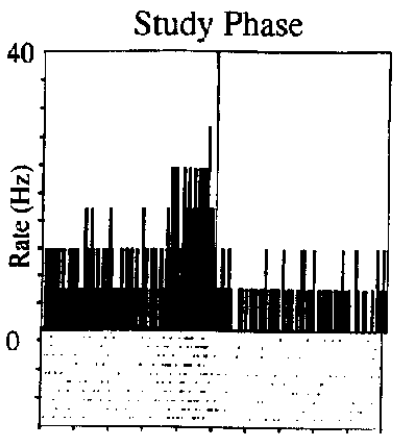

B

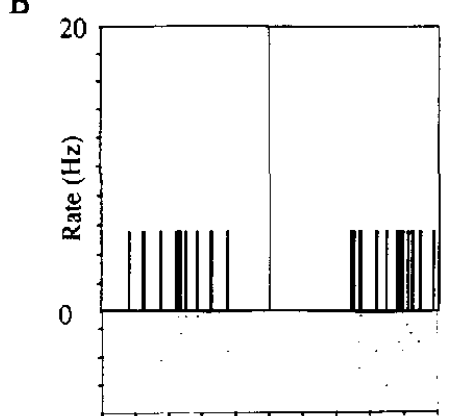

C

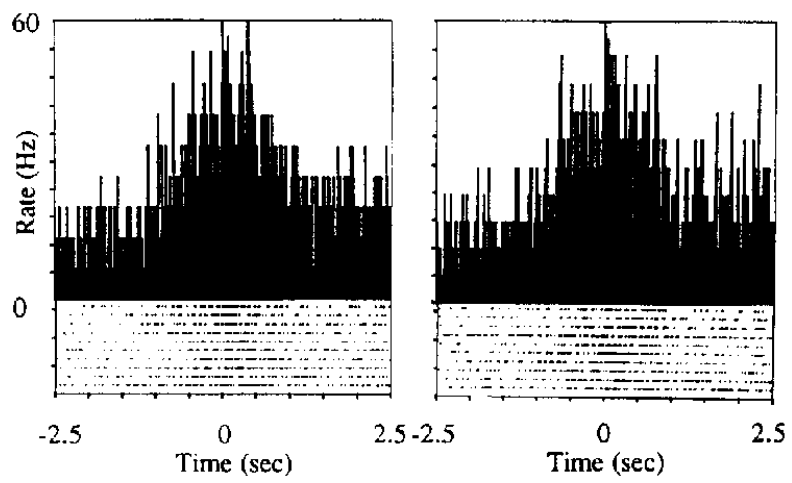

Figure 10. A comparison of the nature of firing patterns for representative biphasic (A), anticipatory inhibition (B), and anticipatory burst $(\mathrm{C})$ neurons between the study and test phases of each trial. Only firing for high reward arms is shown. Note that no difference is observable between the different phases of the memory trial.

critical in contextual fear conditioning (Maren \& Fanselow, 1995; Muller, Corodimas, Fridel, \& LeDoux, 1997).

If the HPC does send a contextual signal to the BLA, then it might be expected that BLA recordings on the present task

Figure 9. Spot rate diagrams indicating place field firing biases for three neurons that were determined to be spatial. Dots represent locations occupied by the rat. Circle size is linearly related to neuronal firing rate. Vector lines projecting from the circles represent the direction faced by the rat during action potential discharge. One cell had a field distributed in the northeast quadrant of the maze (A). Another was focused on the center platform (B). The cell in panel $\mathrm{C}$ demonstrated a tendency to fire in the outbound direction, especially on the southern portions of the maze. This cell was also determined to be an inhibition at encounter neuron. 


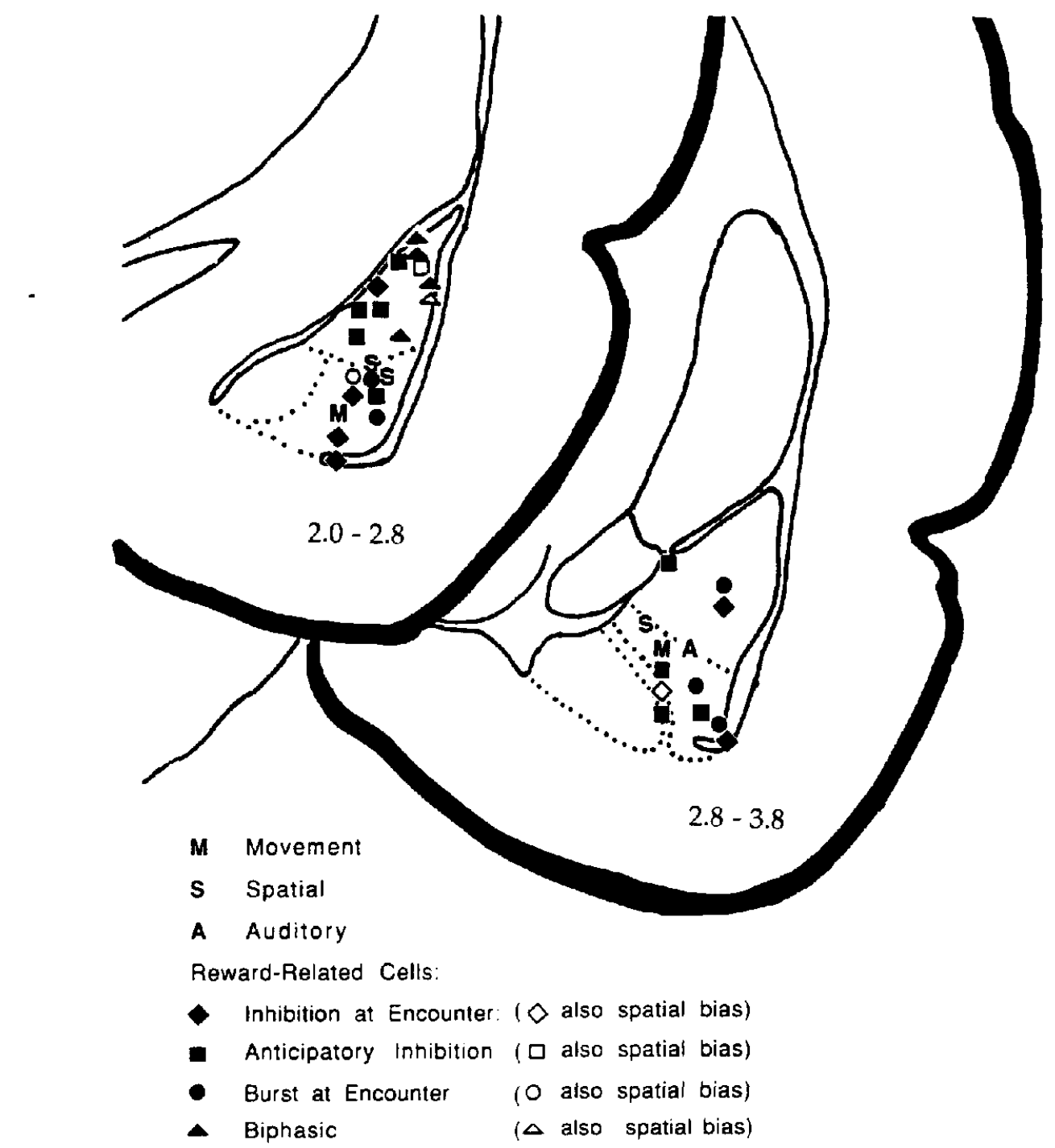

Figure 11. Location of correlated neurons within the basolateral nuclei of the amygdala (BLA). Placement measurements are in millimeters posterior to bregma. Reward neurons are represented as shapes; other neuron types are shown as letters. Reward neurons that also showed spatial selectivity are represented as the outline of the appropriate shape. Note that biphasic neurons were located in the anterior dorsal regions of the BLA and that four of five burst neurons were located ventrally. Other correlates are spread relatively proportionately throughout the structure.

would uncover spatially sensitive reward-related cells. The current data did not show such a tendency. It has been argued previously (Mizumori, Garcia, Raja, \& Volpe, 1995; Mizumori, Lavoie, \& Kalyani, 1996) that the less specific nature of HPC place fields in the subiculum relative to CA1 or CA3, which in turn are less selective than place fields in the dentate gyrus (Barnes, McNaughton, Mizumori, Leonard, \& Lin, 1990; Jung \& McNaughton, 1993; Mizumori, McNaughton, Barnes, \& Fox, 1989; Sharp \& Green, 1994) may be the result of the progressive integration of nonspatial information with spatial representations within the HPC. Given that the major afferents to the BLA from the HPC are from the subiculum and entorhinal cortex, two regions that show comparatively diffuse spatial signaling (Mizumori et al., 1992; Quirk, Muller, Kubie, \& Ranck, 1992; Sharp \& Green, 1994 ), it is likely that the BLA does not receive a precise location signal. Rather, the spatial information received by the BLA may be contextually based. This would explain our observations of low numbers of neurons with distinct location fields, as well as the small number of cells with both spatial and reward-related correlates.

These data suggest that the BLA is part of an integrated system that can, at least under certain circumstances, modulate navigational behaviors of the rat. In particular, the BLA may make a conditional contribution to spatial learning circuits by relaying reward magnitude information when 
such a variable becomes a salient feature of the spatial context. Although it is unlikely that the BLA is the only source of positive affective input into the VS, it may contribute to the limbic-motor interface by providing information regarding the affective nature of salient cues and cue arrays. Certainly, explorations into other structures that are interconnected with the BLA and VS can help clarify the roles of each on the nature of their contribution to the integration of reward with spatial and other information within the striatum.

\section{References}

Amaral, D. G., Price, J. L., Pitkanen, A., \& Carmichael, S. T. (1992). Anatomical organization of the primate amygdaloid complex. In J. P. Aggleton (Ed.), The amygdala: Neurobiological aspects of emotion, memory, and mental dysfunction (pp. 1-66). New York: Wiley-Liss.

Barnes, C. A., McNaughton, B. L., Mizumori, S. J. Y., Leonard, B. W., \& Lin, L.-H. (1990). Comparison of spatial and temporal characteristics of neuronal activity in sequential stages of hippocampal processing. Progress in Brain Research, 83, $287-300$

Bordi, F., \& LeDoux, J. E. (1992). Sensory tuning beyond the sensory system: An initial analysis of auditory properties of neurons in the lateral amygdaloid nucleus and overlying areas of the striatum. Journal of Neuroscience, 12, 2493-2503.

Breese, C. R., Hampson, R. E., \& Deadwyler, S. (1989). Hippocampal place cells: Stereotypy and plasticity. Journal of Neuroscience, 9, 1097-1111.

Cador, M., Robbins, T. W., \& Everitt, B. J. (1989). Involvement of the amygdala in stimulus-reward associations: Interaction with the ventral striatum. Neuroscience, 30, 77-86.

Canteras, N. S., \& Swanson, L. W. (1992). Projections of the ventral subiculum to the amygdala, septum, and hypothalamus: A PHAL anterograde tract-tracing study in the rat. Journal of Comparative Neurology, 324, 180-194.

De Olmos, J., Alheid, G. F., \& Beltramino, C. A. (1985). Amygdala. In G. Paxinos (Ed.), The rat nervous system (pp. 233-334). Orlando, FL: Academic Press.

Eichenbaum, H., Kuperstein, M., Fagan, A., \& Nagode, J. (1987). Cue-sampling and goal-approach correlates of hippocampal unit activity in rats performing an odor-discrimination task. Journal of Neuroscience, 7, 716-732.

Everitt, B., Cador, M., \& Robbins, T. W. (1989). Interactions between the amygdala and ventral striatum in stimulus-reward assaciations: Studies using a second-order schedule of sexual reinforcement. Neuroscience, 30, 63-75.

Everitt, B. J., Morris, K. A., O'Brien, A., \& Robbins, T. W. (1991). The basolateral amygdala-ventral striatal system and conditioned place preference: Further evidence of limbic-striatal interactions underlying reward-related processes. Neuroscience, $42,1-18$.

Finch, D. M. (1996). Neurophysiology of converging synaptic inputs from the rat prefrontal cortex, amygdala, midline thalamus, and hippocampal formation onto single neurons of the caudate/putamen and nucleus accumbens. Hippocampus, 6, 495-512.

Floresco, S. B., Seamans, J. K., \& Phillips, A. G. (1997). Selective roles for hippocampal, prefrontal cortical, and ventral striatal circuits in radial-arm maze tasks with or without a delay. Journal of Neuroscience, 17, 1880-1890.
Gaffan, D., \& Harrison, S. (1987). Amygdalectomy and disconnection in visual learning for auditory secondary reinforcement by monkeys. Journal of Neuroscience, 7, 2285-2292.

Gloor, P. (1997). The temporal lobe and limbic system. New York: Oxford University Press.

Groenewegen, H. J., Vermeulen-Van der Zee, E., Te Kortschot, A., \& Witter, M. P. (1987). Organization of the projections from the subiculum to the ventral striatum in the rat. A study using anterograde transport of phaseolus vulgaris leucoagglutinin. Neuroscience, 23, 103-120.

Hatfield, T., Han, J.-S., Conley, M., Gallagher, M., \& Holland, P. (1996). Neurotoxic lesions of basolateral, but not central, amygdala interfere with Pavlovian second-order conditioning and reinforcer devaluation effects. Journat of Neuroscience, 16, $5256-5265$.

Hitchcock, J. M., \& Davis, M. (1986). Lesions of the amygdala, but not of the cerebellum or red nucleus, block conditioned fear as measured with the potentiated startle paradigm. Behavioral Neuroscience, 100, 11-22.

Hitchcock, J. M., \& Davis, M. (1987). Fear-potentiated startle using an auditory conditioned stimulus: Effect of lesions of the amygdala. Physiology of Behavior, 39, 403-408.

Jung, M. W., \& McNaughton, B. L. (1993). Spatial selectivity of unit activity in the hippocampal granular layer. Hippocampus, 3, 165-182.

Kapp, B. S., Frysinger, R. C., Gallagher, M., \& Haselton, J. (1979). Amygdala central nucleus lesions: Effects on heart rate conditioning in the rabbit. Physiology of Behavior, 23, 1109-1117.

Kelley, A. E., \& Domesick, V. B. (1982). The distribution of the projection from the hippocampal formation to the nucleus accumbens in the rat: An anterograde- and reterogradehorseradish peroxidase study. Neuroscience, 7, 2321-2335.

Kelley, A. E., Domesick, V. B., \& Nauta, W. J. H. (1982). The amygdalostriatal projection in the rat-An anatomical study by anterograde and retrograde tracing methods. Neuroscience, 7 , 615-630.

Kesner, R. P., \& Williams, J. M. (1995). Memory for magnitude of reinforcement: Dissociation between the amygdala and hippocampus. Neurobiology of Learning and Memory, 64, 237-244.

Lavoie, A. M., \& Mizumori, S. J. Y. (1994). Spatial, movement and reward-sensitive discharge by medial ventral striatum neurons of rats. Brain Research, 638, 157-168.

LeDoux, J. E., Cicchetti, P., Xagoraris, A., \& Romanski, L. M. (1990). The lateral amygdaloid nucleus: Sensory interface of the amygdala in fear conditioning. Journal of Neuroscience, 10 , $1062-1069$

Luskin, M. B., \& Price, J. L. (1983). The topographic organization of associational fibers of the olfactory system in the rat, including centrifugal fibers to the olfactory bulb. Journal of Comparative Neurology, 216, 264-291.

Maren, S., Aharonov, G., \& Fanselow, M. S. (1996). Retrograde abolition of conditional fear after excitotoxic lesions in the basolateral amygdala of rats: Absence of a temporal gradient. Behavioral Neuroscience, 110, 718-726.

Maren, S., \& Fanselow, M. S. (1995). Synaptic plasticity in the basolateral amygdala induced by hippocampal formation stimulation in vivo. Journal of Neuroscience, 15, 7548-7564.

McDonald, A. J. (1991). Topographical organization of amygdaloid projections to the caudatoputamen, nucleus accumbens, and related striatal-like areas of the rat brain. Neuroscience, 44 , 15-33.

McDonald, R. J., \& White, N. M. (1993). A triple dissociation of 
memory systems: Hippocampus, amygdala, and dorsal striatum. Behavioral Neuroscience, 107, 3-22.

McGeorge, A. J., \& Faull, R. L. M. (1989). The organization of the projection from the cerebral cortex to the striatum in the rat. Neuroscience, 29, 503-537.

McNaughton, B. L., Barnes, C. A., Meltzer, J., \& Sutherland, R. J. (1989). Hippocampal granules are necessary for normal spatial learning but not for spatially-selective pyramidal cell discharge. Experimental Brain Research, 78, 485-496.

McNaughton, B. L., Barnes, C. A., \& O'Keefe, J. A. (1983). The contributions of position, direction, and velocity to single unit activity in the hippocampus of freely moving rats. Experimental Brain Research, 52, 41-49.

McNaughton, B. L., O'Keefe, J., \& Barnes, C. A. (1983). The stereotrode: A new technique for simultaneous isolation of several single units in the central nervous system from multiple unit records. Journal of Neuroscience Methods, 8, 391-397.

Mello, L. E. A. M., Tan, A. M., \& Finch, D. M. (1992a). Convergence of projections from the rat hippocampal formation, medial geniculate and basal forebrain onto single amygdaloid neurons: An in vivo extra- and intracellular electrophysiological study. Brain Research, 587, 24-40.

Mello, L. E. A. M., Tan, A. M., \& Finch, D. M. (1992b). GABAergic synaptic transmission in projections from the basal forebrain and hippocampal formation to the amygdala: An in vivo iontophoretic study. Brain Research, 587, 41-48.

Mizumori, S. J. Y., Garcia, P. A., Raja, M. A., \& Volpe, B. T. (1995). Spatial- and locomotion-related neural representation in rat hippocampus following long-term survival from ischemia. Behav ioral Neuroscience, 109, 1081-1094.

Mizumori, S. J. Y., Lavoie, A. M., \& Kalyani, A. (1996). Redistribution of spatial representation in the hippocampus of aged rats performing a spatial memory task. Behavioral Neuroscience, $110,1006-1016$.

Mizumori, S. J. Y., McNaughton, B. L., Barnes, C. A., \& Fox, K. B. (1989). Preserved spatial coding in hippocampal CAl pyramidal cells during reversible suppression of $\mathrm{CA} 3$ output: Evidence for pattern completion in hippocampus. Journal of Neuroscience, 9 , 3915-3928.

Mizumori, S. J. Y., Ward, K. E., \& Lavoie, A. M. (1992). Medial septal modulation of entorhinal single unit activity in anesthetized and freely moving rats. Brain Research, 570, 188-197.

Mogenson, G. J., Brudzynski, S. M., Wu, M., Yang, C. R., \& Yim, C. C. Y. (1993). From motivation to action: A review of dopaminergic regulation of limbic-nucleus accumbens-ventral pallidumpedunculopontine nucleus circuitries involved in limbic-motor integration. In P. W. Kalivas \& C. D. Barnes (Eds.), Limbic motor circuits and neuropsychiatry (pp. 193-236). Ann Arbor, MI: CRC Press.

Morris, R. G. M., Garrud, P., Rawlins, J. N. P., \& O'Keefe, J. (1982). Place navigation impaired in rats with hippocampal lesions. Nature, 297, 681-683.

Muller, J., Corodimas, K. P., Fridel, Z., \& LeDoux, J. E. (1997). Functional inactivation of the lateral and basal nuclei of the amygdala by muscimol infusion prevents fear conditioning to an explicit conditioned stimulus and to contextual stimuli. Behavioral Neuroscience, 111, 683-691.

Muller, R. U., Kubie, J. L., \& Ranck, J. B., Jr. (1987). Spatial firing patterns of hippocampal complex-spike cells in a fixed environment. Journal of Neuroscience, 7, 1935-1950.

Muramoto, K., Ono, T., Nishijo, H., \& Fukuda, M. (1993). Rat amygdaloid neuron responses during auditory discrimination. Neuroscience, 52, 621-636.
Nishijo, H., Ono, T., \& Nishino, H. (1988a). Single neuron responses in amygdala of alert monkey during complex sensory stimulation with affective significance. Journal of Neuroscience, $8,3570-3583$.

Nishijo, H., Ono, T., \& Nishino, H. (1988b). Topographic distribution of modality-specific amygdalar neurons in alert monkey. Journal of Neuroscience, 8, 3556-3569.

O'Donnell, P., \& Grace, A. A. (1995). Synaptic interactions among excitatory afferents to nucleus accumbens neurons: Hippocampal gating of prefrontal cortical input. Journal of Neuroscience, $15,3622-3639$.

O'Keefe, J., \& Dostrovsky, J. (1971). The hippocampus as a spatial map. Preliminary evidence from unit activity in the freely moving rat. Brain Research, 34, 171-175.

Olton, D., Branch, M., \& Best, P. J. (1978). Spatial correlates of hippocampal unit activity. Experimental Neurology, 58, 387-409.

Ottersen, O. P. (1982). Connections of the amygdala of the rat. IV: Corticoamygdaloid and intraamygdaloid connections as studies with axonal transport of horseradish peroxidase. Journal of Comparative Neurology, 205, 30-48.

Quirk, G. J., Muller, R. U., Kubie, J. L., \& Ranck, J. B., Jr. (1992). The positional firing properties of medial entorhinal neurons: Description and comparison with hippocampal place cells. Journal of Neuroscience, 12, 1945-1963.

Quirk, G. J., Repa, J. C., \& LeDoux, J. E. (1995). Fear conditioning enhances short-latency auditory responses of lateral amygdala neurons: Parallel recordings in the freely behaving rat. Neuron, $15,1-20$.

Ranck, J. B., Jr. (1973). Studies on single neurons in dorsal hippocampus formation and septum in unrestrained rats. Part I. Behavioral correlates and firing repertoires. Experimental Neurology, 41, 461-535.

Salinas, J. A., Packard, M. G., \& McGaugh, J. L. (1993). Amygdala modulates memory for changes in reward magnitude: Reversible posttraining inactivation with lidocaine attenuates the response to a reduction in reward. Behavioral Brain Research, 59, 153-159.

Sanghera, M. K., Rolls, E. T., \& Roper-Hall, A. (1979). Visual responses of neurons in the dorsolateral amygdala of the alert monkey. Experimental Neurology, 63, 610-626.

Sesack, S. R., Deutch, A. Y., Roth, R. H., \& Bunney, B. S. (1989). Topographical organization of the efferent projections of the medial prefrontal cortex in the rat: An anterograde tract-tracing study with Phaseolus vugaris leucoagglutinin. Journal of Comparative Neurology, 290, 213-242.

Sharp, P. E., \& Green, C. (1994). Spatial correlates of firing patterns of single cells in the subiculum of the freely moving rat. Journal of Neuroscience, 14, 2339-2356.

Speakman, A., \& O'Keefe, J. (1990). Hippocampal complex spike cells do not change their place fields if the goal is moved within a cue controlled environment. European Journal of Neuroscience, 2, 544-555.

Swanson, L. W. (1982). The projections of the ventral tegmental area and adjacent regions: $A$ combined fluorescent retrograde tracer and immunofluorescence study in the rat. Brain Research Bulletin, 9, 321-353.

Turner, B. H., \& Herkenham, M. (1991). Thalamoamygdaloid projections in the rat: A test of the amygdala's role in sensory processing. Journal of Comparative Neurology, 313, 295-325.

Witter, M. P., Groenewegen, H. J., Lopes Da Silva, F. H., \& Lohman, A. H. M. (1989). Functional organization of the 
extrinsic and intrinsic circuitry of the parahippocampal region. Progress in Neurobiology; 33, 161-253.

Yajeya, J., De La Fuente Juan, A., Merchan, M. A., Riolobos, A. S., Heredia, M., \& Criado, J. M. (1997). Cholinergic responses of morphologically and electrophysiologically characterized neurons of the basolateral complex in rat amygdala slices. Neuroscience, 78, 731-743.

Yang, C. R., \& Mogenson, G. J. (1985). An electrophysiological study of the neural projections from the hippocampus to the ventral pallidum and the subpallidal areas by way of the nucleus accumbens. Neuroscience, 15, 1015-1024.

Yim, C. Y., \& Mogenson, G. J. (1982). Response of nucleus accumbens neurons to amygdala stimulation and its modification by dopamine. Brain Research, 239, 401-415.

Yim, C. Y., \& Mogenson, G. J. (1983). Response of ventral pallidal neurons to amygdala stimulation and its modulation by dopamine projections to nucleus accumbens. Journal of Neurophysiology, 50, 148-161.
Received September 22, 1997

Revision received December 8, 1997

Accepted December 10, 1997

\section{American Psychological Association SUBSCRIYTION Claims INFORMATION}

Today's Date:

We provide this form to assist members, institutions, and nonmember individuals with any subscription problems. With the appropriate information we can begin a resolution. If you use the services of an agent, please do NOT duplicate claims through them and directly to us. PLEASE PRINT CLEARLY AND IN INK IF POSSIBLE.

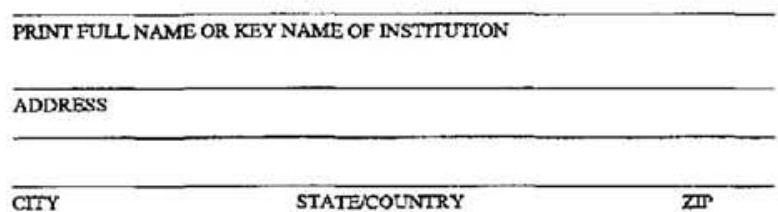

YOUR NAME AND PHONE NUMBER

TITLE

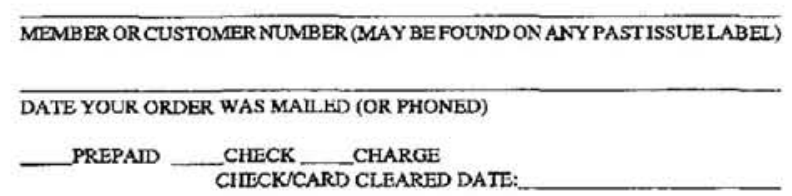

(If possible, send a copy, froat and back, of your cancelled chock to help us is ow reseazch of your clnim.)

ISSUES: __ MISSDNG DAMAGED
NUMBER OR MONTH

Thank you. Once a claim is received and resolved, delivery of replacement issues routinely takes 4-6 weeks.

(TO BE FILLED OUT BY APA STAFF)

DATE RECEIVED:

ACTION TAKEN:

STAFF NAME:
DATE OF ACTION:

INV. NO. \& DATE:

LABEL NO. \& DATE:

Send this form to APA Subscription Claims, 750 First Street, NE, Washington, DC $20002-4242$

PLEASE DO NOT REMOVE. A PHOTOCOPY MAY BE USED. 